\title{
Analysis of US Sector of Services with a New Fama-French 5-Factor Model
}

\author{
Quan Yang1, Liuling Li², Qingyu Zhu³, Bruce Mizrach ${ }^{4}$ \\ ${ }^{1}$ College of Tourism and Service Management, Nankai University, Tianjing, China \\ ${ }^{2}$ Economics School, Nankai University, Tianjing, China \\ ${ }^{3}$ Department of Computer Science, The University of Hong Kong, Hong Kong, China \\ ${ }^{4}$ Economics Department, Rutgers University, New Brunswick, NJ, USA \\ Email: yangquandali@foxmail.com, liliuling@nankai.edu.cn, zhuqingyu_cs@outlook.com, mizrach@econ.rutgers.edu
}

\author{
How to cite this paper: Yang, Q., Li, L.L., \\ Zhu, Q.Y. and Mizrach, B. (2017) Analysis \\ of US Sector of Services with a New Fa- \\ ma-French 5-Factor Model. Applied Ma- \\ thematics, 8, 1307-1319. \\ https://doi.org/10.4236/am.2017.89096 \\ Received: August 24, 2017 \\ Accepted: September 18, 2017 \\ Published: September 21, 2017 \\ Copyright () 2017 by authors and \\ Scientific Research Publishing Inc. \\ This work is licensed under the Creative \\ Commons Attribution International \\ License (CC BY 4.0). \\ http://creativecommons.org/licenses/by/4.0/
}

\begin{abstract}
In this paper, we empirically test a new model with the data of US services sector, which is an extension of the 5-factor model in Fama and French (2015) [1]. 3 types of 5 factors (Global, North American and US) are compared. Empirical results show the Fama-French 5 factors are still alive! The new model has better in-sample fit than the 5-factor model in Fama and French (2015).
\end{abstract}

\section{Keywords}

Fama-French 5-Factor Model (FF5), Standardized Standard Asymmetric Exponential Power Distribution (SSAEPD), EGARCH

\section{Introduction}

After the Capital Asset Pricing Model (CAPM) was created by Sharpe (1964) [2] and Lintner (1965) [3], it makes a fundamental contribution to understand the relationship between expected returns and market risks. Fama and French (1993) added size and book-to-market factors into the CAPM, many empirical results show it's capable to explain the stock returns better than the CAPM. After that, many new factor models are developed. Panel A of Table 1 documents the development of the factor model in stock market. For example, Carhart (1997) [4] introduced a Carhart 4-factor (C) model by augumenting the Fama-French 3-factor (FF3) model with momentum factor which can explain the short-term persistence in expected returns. Chan and Faff (2005) [5] advocated a liquidity-agumented FF3 model by using Australian data and find the liquidity factor is very robust to sensitivity checks. Connor, Hagmann and Linton (2012) 
Table 1. Researches about the Fama-French 5-factor Model.

\begin{tabular}{|c|c|c|c|c|c|}
\hline \multirow[t]{2}{*}{ Author (Year) } & Research Purpose & \multirow[t]{2}{*}{ Model } & \multicolumn{3}{|c|}{ Data } \\
\hline & & & Country & Factors & Frequency \& Period \\
\hline & \multicolumn{5}{|c|}{ Panel A: Development of Factor Model } \\
\hline Fama et al. (1993) [16] & CAPM Extension & FF3 & USA & Mkt, SMB, HML, WML & M1963:7-1991:12 \\
\hline Carhart (1997) & FF3 Extension & CAPM, FF3, C & USA & Mkt, SMB, HML, WML & M1962:1-1993:12 \\
\hline Griffin (2002) [17] & FF3 Extension & $\begin{array}{c}\text { Domestic or } \\
\text { International FF3 }\end{array}$ & Global & Mkt, SMB, HML & M1981:1995:12 \\
\hline Chan et al. (2005) [18] & FF3 Extension & FF3 with IML & Australia & Mkt, SMB, HML, IML & M1990:1-1998:12 \\
\hline Fama et al. (2012) [19] & Model Comparison & $\begin{array}{c}\text { Global or Local CAPM, } \\
\text { FF3, C }\end{array}$ & Global & Mkt, SMB, HML, WML & M1990:11-2011:3 \\
\hline Connor et al. (2012) & C Extension & C with VOL & USA & $\begin{array}{c}\text { Mkt, SMB, HML, WML, } \\
\text { VOL }\end{array}$ & M1970-2007 \\
\hline Chai et al. (2013) [20] & C Extension & C with IML & Australia & $\begin{array}{l}\text { Mkt, SMB, HML, WML, } \\
\text { IML }\end{array}$ & M1982:1-2010:12 \\
\hline Fama et al. (2013) [21] & FF3 Extension & FF4 & USA & Mkt, SMB, HML, RMW & M1963:7-2012:12 \\
\hline Yang (2013) & FF3 Extension & $\begin{array}{c}\text { FF3 with SSAEPD, } \\
\text { EGARCH }\end{array}$ & USA & Mkt, SMB, HML & M1926-2011 \\
\hline Hou et al. (2014) & Model Comparison & FF5, C, q-factor & USA & $\begin{array}{l}\text { Mkt, SMB, RMW, } \\
\text { CMA, WML, HML }\end{array}$ & M1972:1-2011:12 \\
\hline Fama et al. (2015a) & FF4 Extension & FF5 & USA & $\begin{array}{l}\text { Mkt, SMB, HML, } \\
\text { RMW, CMA }\end{array}$ & M1963:7-2013:12 \\
\hline \multirow[t]{2}{*}{ Zhu (2016) } & FF5 Extension & $\begin{array}{c}\text { FF5 with SSAEPD, } \\
\text { EGARCH }\end{array}$ & USA & $\begin{array}{l}\text { Mkt, SMB, HML, } \\
\text { RMW, CMA }\end{array}$ & M1963:7-2013:12 \\
\hline & \multicolumn{5}{|c|}{ Panel B: Researches for Fama-French 5-Factor Model } \\
\hline Fama et al. (2014) & Model Comparison & $\begin{array}{l}\text { CAPM, FF3, FF4, FF5, } \\
\text { FF5 with WML }\end{array}$ & USA & $\begin{array}{l}\text { Mkt, SMB, HML, } \\
\text { RMW, CMA, WML }\end{array}$ & M1963:7-2014:12 \\
\hline Hou et al. (2015) & Model Comparison & FF5, C, q-factor & USA & $\begin{array}{l}\text { Mkt, SMB, HML, } \\
\text { RMW, CMA, WML }\end{array}$ & M1967:1-2013:12 \\
\hline Harshita et al. (2015) & Model Comparison & CAPM, FF3, FF5 & India & $\begin{array}{c}\text { Mkt, SMB, HML, } \\
\text { RMW, CMA }\end{array}$ & M1999:10-2014:9 \\
\hline Fama et al. (2015b) & Empirical Tests & FF5 & Global & $\begin{array}{l}\text { Mkt, SMB, HML, } \\
\text { RMW, CMA }\end{array}$ & M1990:7-2014:9 \\
\hline Chiah et al. (2016) & Empirical Tests & FF3, C, FF5 & Australia & $\begin{array}{c}\text { Mkt, SMB, HML, PMU, } \\
\text { LMH }\end{array}$ & M:1982:1-2013:12 \\
\hline Bin Guo et al. (2017) & Empirical Tests & FF5 & China & $\begin{array}{l}\text { Mkt, SMB, HML, } \\
\text { RMW, CMA,CMAB }\end{array}$ & M:1995:7-2014:6 \\
\hline Rehab et al. (2016) & Empirical Tests & FF5 & Egypt & $\begin{array}{l}\text { MKT, SMB, HML, } \\
\text { HEMLE, HSMLS, } \\
\text { HDMLD, IML and } \\
\text { WML }\end{array}$ & M:2005:7-2013:7 \\
\hline Fama et al. (2016) & Empirical Tests & FF5 & Global & $\begin{array}{l}\text { Mkt, SMB, HML, } \\
\text { RMW, CMA }\end{array}$ & M:1990:7-2015:12 \\
\hline
\end{tabular}

Notes: “-" means that no information is available in this paper; CAPM = Capital Asset Pricing Model; FF3 = Fama and French (1993) 3-factor model; FF4 = Fama and French 4-factor model (2013); FF5 = Fama and French (2015) 5-factor model; C = Carhart (1997) 4-factor; q-factor = Hou, Xue, and Zhang (2012) q-factor model; 14-factor $=$ Harvay and Liu (2015) 14-factor model; Mkt $=$ Market; SMB $=$ Size; HML = Book-to-market; WML = Momentum; IMV = liquidity; $\mathrm{Vol}=$ Own-volatility; RMW = Profitability; CMA = Investment; PMU = Profitable Minus Unprofitable; HML = High Minus Low; HAC-adjusted OLS = Newey-West heteroskedasticity; and autocorrelation-adjusted OLS. WLS = Weighted least squares. 
[6] considered a five-factor extension of the $\mathrm{C}$ model which suggests an own-volatility factor.

In 2015, Fama and French proposed 5 factor model(FF5), it adds profitability and investment factors into their 3-factor model proposed in 1993. Since then, many studies about Fama-French 5-factor (FF5) model have been done. Panel B of Table 1 presents the researches for the FF5 Model. And these researches mainly apply the FF5 model to empirical stock markets and compare the FF5 model with others.

For example, Hou, Xue and Zhang (2015) [7] found that the 4-factor q-model created by Hou, Xue and Zhang (2014) [8] performs better than the FF5 model in US market. Harshita et al. (2015) [9] pointed out that the FF5 model works better in India than CAPM and FF3 model. Fama and French (2015) [9] also showed that the FF5 model can explain quite well for North America and other 3 regions. Mardy et al. (2016) [10] empirically investigated the FF5 Model in Australia, finding after adding the profitability and investment factors, FF5 model is really able to explain more asset pricing anomalies than other competing asset pricing models (like Fama-French 3-factor model and Carhart 4-factor model).

Although FF5 model has better performance in many case, it's not adapted to every situation. Fama and French (2017) [11] analyzed the international market and found that the investment factor CMA is redundant for Europe, Japan and Asia Pacific. Meanwhile, Fama and French also found the new factors' performance are different for small and big stock market. And for different regions, factors' performance also exist difference. Besides, Guo et al. (2017) [12] found that the profitability factor significantly improves the description of average return, and investment pattern in average returns is weak in China stock market.

In 2017, Li et al. [13] added non-normal errors of SSAEPD proposed by Zhu and Zinde-Walsh (2009) [14] and the EGARCH-type volatilities suggested in Nelson (1991) [15] to extend the 5 factor model in Fama and French (2015). They called this new model as FF5-SSAEPD-EGARCH. Both EGARCH equation and SSAEPD can be used to capture the fat-tailedness. SSAEPD can be used to capture the asymmetric kurtosis of data. Thus, in this paper we use the data of US services industry to empirically test the new model and compare it with Fama-French 5 factors (FF5). In this paper, following two hypotheses will be tested:

1) With EGARCH-type volatilities and SSAEPD errors, are Fama-French 5 factors still alive?

2) Can this new model explain services industry better than the 5 factor model in Fama and French (2015)?

To answer these questions, we run simulation to test the validity of MatLab program used in this paper. Then, the industry of services in US are analyzed. Data are downloaded from the French's Data Library, and the sample period is from Jul. 1990 to Feb. 2017. Method of Maximum Likelihood Estimation (MLE) is used to estimate the parameters. Likelihood Ratio test (LR) and Kolmogorov-Smirnov test (KS) are used for model diagnostics. Akaike 
Information Criterion(AIC) is used for model comparsion.

We find out the Fama-French 5 factors are still alive. The new model has better in-sample fit than the 5-factor model in Fama and French (2015). The industry of services can earn extra Alpha returns since the constant term in the new model is statistically significant. The Beta $\left(\beta_{1}\right)$ coefficient (for US, North American) is very close to 1 . We also find out models with GARCH-typed volatility fit data better than those with EGARCH-typed volatility. To capture fat-tailedness, GARCH equation is better than non-normal error terms of SSAEPD.

The organization of this paper is as follows: The model and methodology are discussed in Section 2; Empirical results and the model comparisons will be presented in Section 3; Section 4 is the conclusions and future extensions.

\section{Model and Methodology}

\subsection{Models}

\subsubsection{Fama-French 5-Factor Model (FF5-Normal)}

Fama and French(2015) propose a 5-factor model (denoted as FF5) to explain market, size, value, profitability, and investment patterns in expected stock returns, and show this model empirically outperforms their 3 factor model. The 5-factor model is:

$$
\begin{aligned}
R_{t}-R_{f t} & =\beta_{0}+\beta_{1} *\left(R_{m t}-R_{f t}\right)+\beta_{2} * S M B_{t}+\beta_{3} * H M L O_{t} \\
& +\beta_{4} * R M W_{t}+\beta_{5} * C M A_{t}+u_{t}, u_{t} \sim \operatorname{Normal}\left(\mu, \sigma^{2}\right) .
\end{aligned}
$$

where $\theta=\left(\beta_{0}, \beta_{1}, \beta_{2}, \beta_{3}, \beta_{4}, \beta_{5}, \mu, \sigma\right)$ are parameters to be estimated in this model. $R_{t}$ is the rate of return for stock portfolio. $R_{f t}$ is the rate of return for the risk-free asset. $R_{m t}$ is the rate of return for the market. $S M B_{t}$ stands for small market capitalization minus big market capitalization. $H M L O_{t}$ is the high book-to-market ratio minus low book-to-market ratio orthogonalized ${ }^{1}$. $R M W_{t}$ stands for robust operating profitability portfolios minus weak operating profitability portfolios. $C M A_{t}$ stands for conservative investment portfolios minus aggressive investment portfolios. The error term $u_{t}$ is distributed as the Normal. $t=1,2, \cdots, T$.

\subsubsection{FF5-SSAEPD-EGARCH Model}

Li et al. (2016) extend Fama-French(2015) five-factor model by introducing a Standardized Standard Asymmetric Exponential Power Distribution (SSAEPD)

${ }^{1} H_{M L O}$ is the sum of the intercept and the residual from the regression of $H M L_{t}$ on $R_{m t}-R_{f t}, S M B_{t}, R M W_{t}, C M A_{1}$. The reason we use $H M L O_{t}$ is that Fama and French (2015) show $H M L_{t}$ (the high book-to-market ratio minus low book-to-market ratio) is redundant in following 5-factor model.

$$
\begin{gathered}
R_{t}-R_{f t}=\beta_{0}+\beta_{1} *\left(R_{m t}-R_{f t}\right)+\beta_{2} * S M B_{t}+\beta_{3} * H M L_{t}+\beta_{4} * R M W_{t}+\beta_{5} * C M A_{t}+u_{t}, \\
u_{t} \sim \operatorname{Normal}\left(\mu, \sigma^{2}\right), t=1,2, \cdots, T .
\end{gathered}
$$


errors and the EGARCH -type volatilites. The new model we proposed is (denoted as the FF5-SSAEPD-EGARCH model):

$$
\begin{gathered}
R_{t}-R_{f t}=\beta_{0}+\beta_{1}\left(R_{m t}-R_{f t}\right)+\beta_{2} S M B_{t}+\beta_{3} H M L O_{t} \\
\quad+\beta_{4} R M W_{t}+\beta_{5} C M A_{t}+u_{t}, \\
u_{t}=\sigma_{t} z_{t}, z_{t} \sim \operatorname{SSAEPD}\left(\alpha, p_{1}, p_{2}\right), \\
\ln \left(\sigma_{t}^{2}\right)=a+\sum_{i=1}^{s} g\left(z_{t-i}\right)+\sum_{j=1}^{m} b_{j} \ln \left(\sigma_{t-j}^{2}\right), \\
g\left(z_{t-i}\right)=c_{i} z_{t-i}+d_{i}\left[\left|z_{t-i}\right|-E\left(\left|z_{t-i}\right|\right)\right] \\
= \begin{cases}\left(c_{i}+d_{i}\right) z_{t-i}-d_{i} E\left(\left|z_{t-i}\right|\right), & \text { if } z_{t-i} \geq 0, \\
\left(c_{i}-d_{i}\right) z_{t-i}-d_{i} E\left(\left|z_{t-i}\right|\right), & \text { else. }\end{cases}
\end{gathered}
$$

where $\theta=\left(\beta_{0}, \beta_{1}, \beta_{2}, \beta_{3}, \beta_{4}, \beta_{5}, \alpha, p_{1}, p_{2}, a,\left\{b_{j}\right\}_{j=1}^{m},\left\{c_{i}\right\}_{i=1}^{s},\left\{d_{i}\right\}_{i=1}^{s}\right) \quad$ are the parameters to be estimated. Definitions of variables are the same as before. $\sigma_{t}$ is the conditional standard deviation, i.e., volatility. The error term $z_{t}$ is distributed as the Standardized Standard Asymmetric Exponential Power Distribution (SSAEPD) proposed in Zhu and Zinde-Walsh (2009).

\section{-Standardized Standard AEPD (SSAEPD)}

According to Zhu and Zinde-Walsh (2009), the AEPD density has following form ${ }^{2}$ :

$$
f_{\mathrm{AEPD}}(x)=\left\{\begin{array}{l}
\left.\left(\frac{\alpha}{\alpha^{*}}\right) \frac{1}{\sigma} K\left(p_{1}\right) \exp \left(-\frac{1}{p_{1}} \mid \frac{x-\mu}{2 \alpha^{*} \sigma}\right)^{p_{1}}\right), \text { if } x \leq \mu, \\
\left(\frac{1-\alpha}{1-\alpha^{*}}\right) \frac{1}{\sigma} K\left(p_{2}\right) \exp \left(-\frac{1}{p_{2}}\left|\frac{x-\mu}{2\left(1-\alpha^{*}\right) \sigma}\right|^{p_{2}}\right), \text { if } x>\mu .
\end{array}\right.
$$

where $\theta=\left(\alpha, p_{1}, p_{2}, \mu, \sigma\right)$ is the parameter vector. $\mu \in R$ and $\sigma>0$ represent location and scale, respectively ${ }^{3} . \alpha \in(0,1)$ is the skewness parameter. $p_{1}>0$ and $p_{2}>0$ are the left and the right tail parameters, respectively. $K(p)$ and $\alpha^{*}$ are defined as

$$
K(p)=\frac{1}{2 p^{1 / p} \Gamma(1+1 / p)},
$$

${ }^{2} \mathrm{~A}$ convenient reparametrization of Equation (10) is obtained by rescaling, where

$$
\begin{aligned}
& f_{\text {APPD }}(x)=\left\{\begin{array}{l}
\frac{1}{\sigma} \exp \left(-\frac{1}{p_{1}}\left|\frac{x-\mu}{2 \alpha \sigma K\left(p_{1}\right)}\right|^{p_{1}}\right), \text { if } x \leq \mu, \\
\frac{1}{\sigma} \exp \left(-\frac{1}{p_{2}}\left|\frac{x-\mu}{2(1-\alpha) \sigma K\left(p_{2}\right)}\right|^{p_{2}}\right), \text { if } x>\mu .
\end{array}\right. \\
& \theta=\left(\alpha, p_{1}, p_{2}, \mu, \sigma\right)
\end{aligned}
$$

${ }^{3}$ In this case, $\mu$ and $\sigma$ are not the notations for the population mean and the population standard deviation. 


$$
\alpha^{*}=\frac{\alpha K\left(p_{1}\right)}{\alpha K\left(p_{1}\right)+(1-\alpha) K\left(p_{2}\right)} .
$$

If we set the location parameter $\mu=0$ and the scale parameter $\sigma=1$, then we say $X$ is a random variable distributed as Standard AEPD, denote it as $X \sim \operatorname{SAEPD}\left(\alpha, p_{1}, p_{2}, 0,1\right)$. Its $\mathrm{PDF}^{4}$, mean and variance are

$$
\begin{aligned}
& f_{\mathrm{SAEPD}}(x)=\left\{\begin{array}{l}
\left(\frac{\alpha}{\alpha^{*}}\right) K\left(p_{1}\right) \exp \left(-\frac{1}{p_{1}}\left|\frac{x}{2 \alpha^{*}}\right|^{p_{1}}\right), \text { if } x \leq 0, \\
\left(\frac{1-\alpha}{1-\alpha^{*}}\right) K\left(p_{2}\right) \exp \left(-\frac{1}{p_{2}}\left|\frac{x}{2\left(1-\alpha^{*}\right)}\right|^{p_{2}}\right), \text { if } x>0,
\end{array}\right. \\
& E(X)=\frac{1}{B}\left[(1-\alpha)^{2} \frac{p_{2} \Gamma\left(2 / p_{2}\right)}{\Gamma^{2}\left(1 / p_{2}\right)}-\alpha^{2} \frac{p_{1} \Gamma\left(2 / p_{1}\right)}{\Gamma^{2}\left(1 / p_{1}\right)}\right], \\
& \operatorname{Var}(X)=\frac{1}{B^{2}}\left\{(1-\alpha)^{3} \frac{p_{2}^{2} \Gamma\left(3 / p_{2}\right)}{\Gamma^{3}\left(1 / p_{2}\right)}+\alpha^{2} \frac{p_{1}^{2} \Gamma\left(3 / p_{1}\right)}{\Gamma^{3}\left(1 / p_{1}\right)}\right. \\
&\left.-\left[(1-\alpha) \frac{p_{2} \Gamma\left(2 / p_{2}\right)}{\Gamma^{2}\left(1 / p_{2}\right)}-\alpha^{2} \frac{p_{1} \Gamma\left(2 / p_{1}\right)}{\Gamma^{2}\left(1 / p_{1}\right)}\right]^{2}\right\} .
\end{aligned}
$$

Then, if we standardize $X$ with its mean and standard deviation, we can get $Z=\frac{X-E(X)}{\sqrt{\operatorname{Var}(X)}}$, which we call Standardized Standard AEPD (SSAEPD). The PDF of $Z$ can be got by transformation.

$$
\begin{aligned}
f_{\mathrm{SSAEPD}}(Z) & =|J| f_{\mathrm{SAEPD}}(E(X)+Z \sqrt{\operatorname{Var}(X)}) \\
& =\delta f_{\mathrm{SAEPD}}(\omega+Z \delta)
\end{aligned}
$$

where $\omega=E(X),|J|=\delta$ and $\delta=\sqrt{\operatorname{Var}(X)}$, we can get the probability density function (PDF) of the SSAEPD

$$
f_{\mathrm{SSAEPD}}(z)=\left\{\begin{array}{l}
\delta\left(\frac{\alpha}{\alpha^{*}}\right) K\left(p_{1}\right) \exp \left(-\frac{1}{p_{1}}\left|\frac{\omega+z \delta}{2 \alpha^{*}}\right|^{p_{1}}\right), \text { if } z \leq-\frac{\omega}{\delta}, \\
\delta\left(\frac{1-\alpha}{1-\alpha^{*}}\right) K\left(p_{2}\right) \exp \left(-\frac{1}{p_{2}}\left|\frac{\omega+z \delta}{2\left(1-\alpha^{*}\right)}\right|^{p_{2}}\right), \text { if } z>-\frac{\omega}{\delta} .
\end{array}\right.
$$

${ }^{4} \mathrm{~A}$ convenient reparametrization of Equation (14) is obtained by rescaling, where

$$
f_{\text {SAFP }}(x)=\left\{\begin{array}{c}
\exp \left(-\frac{1}{p_{1}}\left|\frac{x}{2 \alpha K\left(p_{1}\right)}\right|^{p_{1}}\right), \text { if } x \leq 0, \\
\exp \left(-\frac{1}{p_{2}}\left|\frac{x}{2(1-\alpha) K\left(p_{2}\right)}\right|^{p_{2}}\right), \text { if } x>0 . \\
\quad \theta=\left(\alpha, p_{1}, p_{2}, 0,1\right)
\end{array}\right.
$$


$E(z)=0, \operatorname{Var}(z)=1$. With $\alpha=0.5, p_{1}=p_{2}=2$, SSAEPD reduces to Normal $(0,1)$.

\subsection{Method of Maximum Likelihood Estimation (MLE)}

We estimate the FF5-SSAEPD-EGARCH model with the method of Maximum Likelihood Estimation (MLE). The likelihood function is

$$
\begin{aligned}
& L\left(\left\{R_{t}-R_{f t}, R_{m t}-R_{f t}, S M B_{t}, H M L O_{t}, R M W_{t}, C M A_{t}\right\}_{t=1}^{T} ; \theta\right) \\
& =\prod_{t=1}^{T} f\left(R_{t}-R_{f t}\right)
\end{aligned}
$$

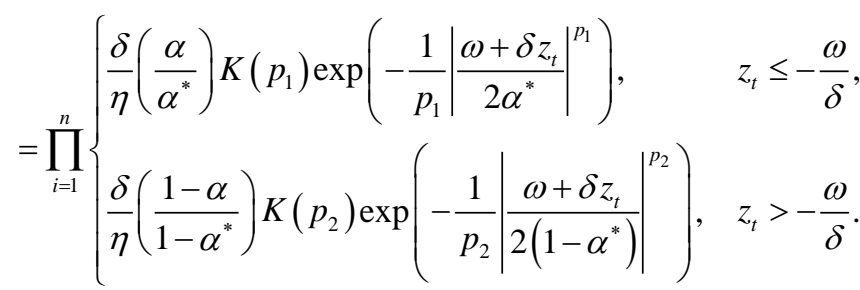

where

$$
\begin{aligned}
& z_{t}=\frac{R_{t}-R_{f t}-\beta_{0}-\beta_{1}\left(R_{m t}-R_{f t}\right)-\beta_{2} S M B_{t}-\beta_{3} H M L O_{t}-\beta_{4} R M W_{t}-\beta_{5} C M A_{t}}{\sigma_{t}}, \\
& \ln \left(\sigma_{t}^{2}\right)=a+\sum_{i=1}^{s} g\left(z_{t-i}\right)+\sum_{j=1}^{m} b_{j} \ln \left(\sigma_{t-j}^{2}\right) \\
& g\left(z_{t-i}\right)=c z_{t-i}+d_{i}\left[\left|z_{t-i}\right|-E\left(\left|z_{t-i}\right|\right)\right], \\
& = \begin{cases}\left(c_{i}+d_{i}\right) z_{t-i}-d_{i} E\left(\left|z_{t-i}\right|\right), & \text { if } z_{t-i} \geq 0, \\
\left(c_{i}-d_{i}\right) z_{t-i}-d_{i} E\left(\left|z_{t-i}\right|\right), & \text { else. }\end{cases}
\end{aligned}
$$

\section{Empirical Analysis}

\subsection{Data}

In this paper, the sector of services in US is analyzed. Monthly return and 3 types of 5 factors (US 5 factors, North American 5 factors and Global 5 factors) ${ }^{5}$ are downloaded from French's Data Library ${ }^{6}$. Sample period is from July 1990 to Feb. 2017. 3 types of 5 factors (US, north American, global) are compared.

Table 2 lists the descriptive statistics calculated by Matlab ${ }^{7}$. The values of skewness are not equal to 0 and those of Kurtosis are not 3. Especially, kurtosis values are all greater than 3 . P-values of JB tests are 0 , which are smaller than

${ }^{5}$ Global 5 factors are constructed by 23 countries, there are Australia, Austria, Belgium, Canada, Switzerland, Germany, Denmark, Spain, Finland, France, Great Britain, Greece, Hong Kong, Ireland, Italy, Japan, Netherlands, Norway, New Zealand, Portugal, Sweden, Singapore, United States. North American 5 factors are construted by Canada and United States. US 5 factors are constructed by United States.

${ }^{6}$ Data source is mba.tuck.dartmouth.edu/pages/faculty/ken.french/data_library.html.

${ }^{7}$ Excess returns are got by portfolio returns minus the risk free rate. 
Table 2. Descriptive statistics (1990:7 to 2017:2, monthly).

\begin{tabular}{|c|c|c|c|c|c|c|c|c|}
\hline & Mean & Med. & Max. & Min. & St.De. & Ske. & Kur. & $\mathrm{P}$ \\
\hline \multicolumn{9}{|c|}{ Panel A: Excess Returns of US Sector of Services } \\
\hline US & 1.00 & 1.74 & 22.22 & -19.16 & 5.98 & -0.30 & 3.97 & 0.00 \\
\hline \multicolumn{9}{|c|}{ Panel B: US 5 factors } \\
\hline ME & 0.65 & 1.19 & 11.35 & -17.23 & 4.27 & -0.68 & 4.26 & 0.00 \\
\hline SMB & 0.19 & 0.07 & 18.73 & -15.28 & 3.11 & 0.47 & 8.05 & 0.00 \\
\hline HML & 0.27 & -0.05 & 12.91 & -11.25 & 3.03 & 0.15 & 5.57 & 0.00 \\
\hline RMW & 0.33 & 0.37 & 13.52 & -19.11 & 2.75 & -0.45 & 13.86 & 0.00 \\
\hline CMA & 0.26 & 0.09 & 9.55 & -6.88 & 2.10 & 0.56 & 5.22 & 0.00 \\
\hline \multicolumn{9}{|c|}{ Panel C: North American 5 factors } \\
\hline $\mathrm{ME}$ & 0.65 & 1.14 & 11.54 & -18.42 & 4.25 & -0.72 & 4.55 & 0.00 \\
\hline SMB & 0.18 & 0.12 & 16.48 & -13.54 & 2.79 & 0.33 & 7.59 & 0.00 \\
\hline HML & 0.24 & 0.19 & 16.75 & -13.36 & 3.24 & 0.56 & 7.69 & 0.00 \\
\hline RMW & 0.32 & 0.28 & 13.13 & -15.32 & 2.43 & 0.14 & 12.25 & 0.00 \\
\hline CMA & 0.30 & 0.02 & 14.23 & -10.03 & 2.67 & 0.93 & 7.63 & 0.00 \\
\hline \multicolumn{9}{|c|}{ Panel D: Global 5 factors } \\
\hline $\mathrm{ME}$ & 0.45 & 0.86 & 11.45 & -19.54 & 4.33 & -0.70 & 4.62 & 0.00 \\
\hline SMB & 0.12 & 0.08 & 8.00 & -8.43 & 1.98 & -0.34 & 5.20 & 0.00 \\
\hline HML & 0.33 & 0.22 & 11.65 & -9.54 & 2.29 & 0.54 & 8.17 & 0.00 \\
\hline RMW & 0.34 & 0.34 & 6.10 & -5.44 & 1.46 & -0.04 & 5.06 & 0.00 \\
\hline CMA & 0.26 & 0.06 & 9.60 & -6.55 & 1.89 & 0.66 & 6.92 & 0.00 \\
\hline
\end{tabular}

Notes: Med. = Median; Max. = Maximum; Min. = Minimum; St.De. = Standard Devistion; Ske. = Skewness; Kur. = Kurtosis; P = englishP-value of Jarque-Bera Test; ME = Market Excess Return; SMB = Small minus Big; HML = High minus Low; RMW = Robust minus Weak; CMA = Conservation minus Aggressive; The null hypothesis of JB test is $H_{0}$ : Data are distributed as $\operatorname{Normal}(0,1)$.

0.05. That means, under $5 \%$ significance level, we can reject the null hypothesis and conclude that data do not follow Normal distribution. Hence, non-Normal error of SSAEPD may be proper. And from Table 2 we can see US 5 factors are very similar to North American 5 factors.

\subsection{Estimation Results}

The estimates are listed in Table 3. For FF5-SSAEPD-EGARCH, the Alpha returns for Global five factors is 0.78 , bigger than the ones calculated from both US five factors and North American five factors ( 0.35 and 0.27 , respectively). And the values of Beta ( $\beta_{1}$ coefficient) for US five factors is close to that from the North American five factors, which is very close to 1 . Meanwhile, the value of $\operatorname{Beta}\left(\beta_{1}\right)$ for Global five factors is 0.81 , which is the smallest. It is interesting to find the coefficient of $\beta_{2}$ is negative for global five factors, which means the small-size effect documented in US market can not be found in the global market. Similar conclusions can be found from model of FF5-Normal. 
Table 3. Estimates.

\begin{tabular}{|c|c|c|c|c|c|c|c|c|c|c|c|c|c|c|c|}
\hline & $\beta_{0}$ & $\beta_{1}$ & $\beta_{2}$ & $\beta_{3}$ & $\beta_{4}$ & $\beta_{5}$ & $\alpha$ & $p_{1}$ & $p_{2}$ & $\mu$ & $\sigma$ & $a$ & $b$ & c & $d$ \\
\hline \multicolumn{16}{|c|}{ Panel A: FF5-SSAEPD-EGARCH } \\
\hline US 5 factors & 0.35 & 1.00 & 0.11 & -0.26 & -0.31 & -0.70 & 0.43 & 1.68 & 1.74 & -0.03 & 1.93 & 0.12 & 0.91 & 0.10 & 0.09 \\
\hline $\begin{array}{l}\text { North American } \\
5 \text { factors }\end{array}$ & 0.27 & 0.97 & 0.04 & -0.29 & -0.25 & -0.65 & 0.43 & 1.70 & 1.79 & 0.03 & 2.01 & 0.10 & 0.94 & -0.01 & 0.16 \\
\hline Global 5 factors & 0.78 & 0.81 & -0.26 & -0.53 & -0.81 & -1.02 & 0.43 & 1.70 & 1.80 & 0.54 & 3.02 & 0.06 & 0.97 & -0.02 & 0.21 \\
\hline \multicolumn{16}{|c|}{ Panel B: FF5-Normal } \\
\hline US 5 factors & 0.33 & 1.02 & 0.12 & -0.26 & -0.27 & -0.77 & - & - & - & 0 & 1.92 & - & - & - & - \\
\hline $\begin{array}{l}\text { North American } \\
5 \text { factors }\end{array}$ & 0.31 & 1.00 & 0.10 & -0.29 & -0.16 & -0.72 & - & - & - & 0 & 1.99 & - & - & - & - \\
\hline Global 5 factors & 0.94 & 0.79 & -0.13 & -0.27 & -0.59 & -1.21 & - & - & - & 0 & 2.95 & - & - & - & - \\
\hline
\end{tabular}

Notes: FF5-Normal is the model used in Fama-French (2015); FF5-SSAEPD-EGARCH is the new 5-factor model suggested by Zhu and Li (2016) supposing the error term meet the EGARCH-type volatilities and SSAEPD errors.

\subsubsection{Fama-French 5 Factors Still Alive}

\section{- Parameter Restriction Tests}

Likelihood Ratio test $(\mathrm{LR})^{8}$ is used to test the significance of regressors in these models. The P-values for Likelihood Ratio tests are listed in Table 4. We find out with non-Normal errors such as SSAEPD and EGARCH-type volatilities, the Fama-French 5 factors are still alive for the sector of services.

Panel A of Table 4 lists the test results for the FF5-SSAEPD-EGARCH model. For example, the P-values of the joint significance test (see column T1) ${ }^{9}$ for all 3 types of 5 factors (US, North Ameirican and Global) are approximately equal to 0 , which means the coefficient of $\beta_{1}, \beta_{2}, \beta_{3}, \beta_{4}$ and $\beta_{5}$ are statistically joint significant under $5 \%$ significance level.

For 3 kinds of five factors, the individual significance tests show $\beta_{1}$ is statistically significant (see column T3). That is, market returns have significant effect on this sector returns. Same is true for $\beta_{3}, \beta_{4}$ and $\beta_{5}$. For $2 / 3$ types of 5 factors, $\beta_{0}$ and $\beta_{2}$ are statistically significant (see column T2 and T4, respectively).

Panel B of Table 4 lists the test results for the FF5-Normal model. For this model, this sector doesn't have a statistically significant coefficient $\beta_{0}$ under $5 \%$ significance level (see column T2) which means they can not earn statistically signicant Alpha returns. But with FF5-SSAEPD-EGARCH model, this sector in both US and Global market have a statistically significant coefficient $\beta_{0}$ under $5 \%$ significance level, expecially we can earn more Alpha return from Global market because $\beta_{0}$ in this market is 0.78 (see Table 3, column 2), the highest among 3 types of 5 factors. Furthermore, the size factor seems statistically significant for $2 / 3$ kinds of 5 factors and is not significant in Global Market ${ }^{10}$.

${ }^{8} \mathrm{LR}$ formula is from Neyman and Pearson (1993) [22]. The equation is:

$\mathrm{LR}=-2 \ln ($ likelihood for null $)+2 \ln ($ likelihood for alternative $)$.

${ }^{9}$ The null hypothesis of the joint significance test is $H_{0}: \beta_{1}=\beta_{2}=\beta_{3}=\beta_{4}=\beta_{5}=0$.

${ }^{10}$ See column T4. 
Table 4. P-values of likelihood ratio test (LR).

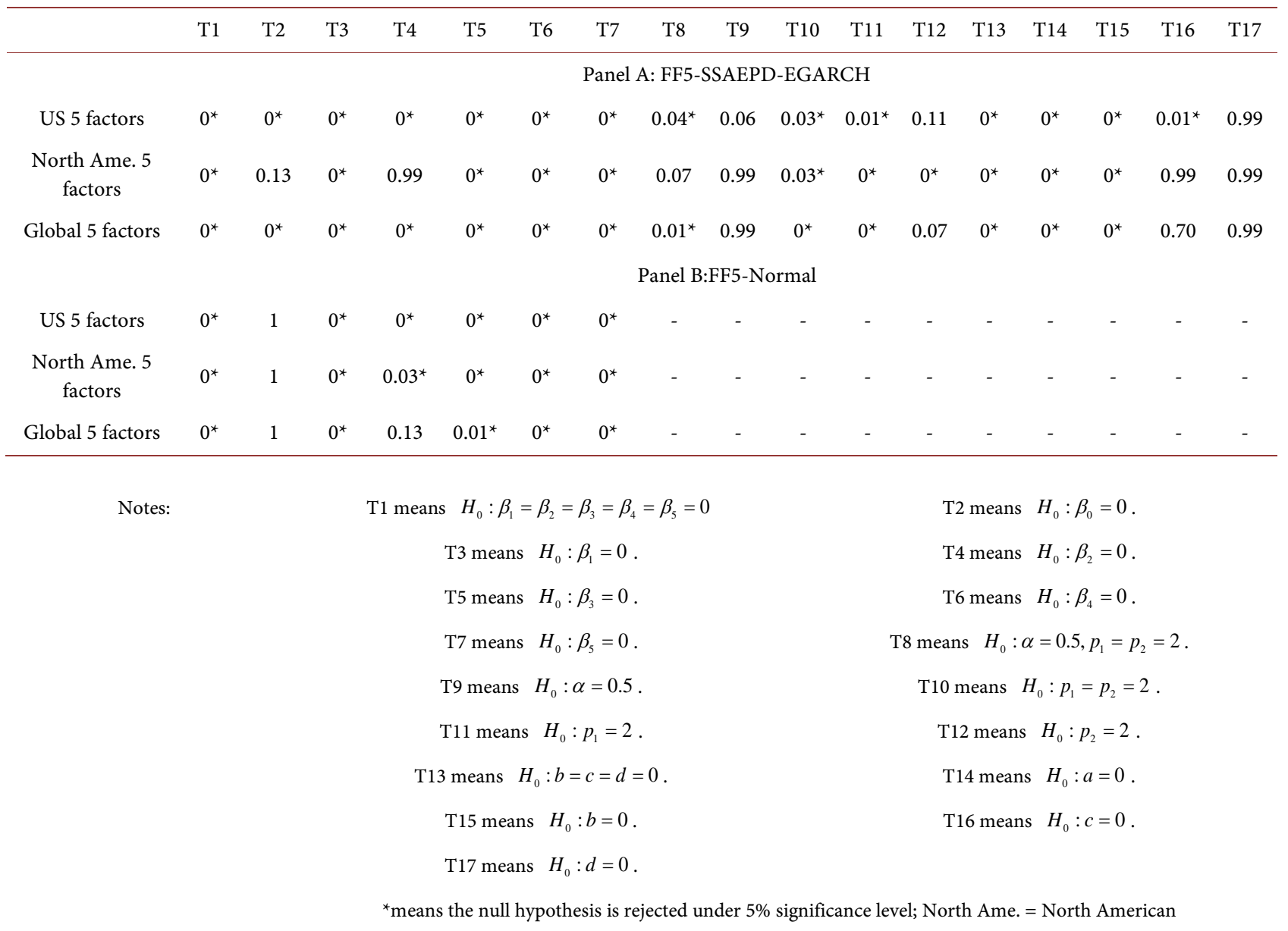

For the FF5-SSAEPD-EGARCH model, among both US 5 factors and Global 5 factors, all individual coefficients in the mean equation are statistically significant. Hence, we conclude that Fama-French 5 factors are alive even if EGARCH and SSAEPD considered.

In this part, some restrictions on the parameters in the EGARCH equation are also tested with Likelihood Ratio test (LR). And the results are also listed in Table 4. Results show the EGARCH-type volatility should be included in Fama-French 5 factor model. For instance, we do the joint significance test for hypothesis $H_{0}: b=c=d=0$. The P-value of the LR are all smaller than the significance level 5\%, which means our EGARCH-type volatilities is necessary, english ARCH and GARCH terms should be added into Fama-French 5-factor model since they are all statistically signicant (see column T13).

Next, we test the parameters in the SSAEPD with same method and the results show englishparameter $\alpha$ is statistically significant equal to 0.5 , so skewnessenglish is not documentedenglish. Non-Normality is confirmed (see column T8, T10, T11, T12). The left and the right tail parametersenglish $\left(p_{1}\right.$ and $\left.p_{2}\right)$ are jointly statistically different from 2 (see column T10). And leftenglish tail is statistically different from 2 in all markets (see column T11) but right tail is only statistically 
different from 2 in North American market (see column T12). i.e., strong left fat-tailedness is documented. Therefore. this new 5-factor model can capture the fat-tailedness better than FF5-Normal model.

- Kolmogorov-Smirnov Test for Residuals

We check the residuals for models with Kolmogorov-Smirnov test (KS). The $\mathrm{P}$-values of KS test are listed in Table 5, the P-value of the Global five factors is 0.07 , greater than $5 \%$, which means under $5 \%$ significance level, the null hypothesis is not rejected and the residuals from FF5-SSAEPD-EGARCH do follow the SSAEPD. 2/3 markets support this result. For the FF5-Normal model ${ }^{11}$, the P-values of the KS test are also listed in Table 5. All of them have smaller P-values than 0.05 , which means reject the nulls. Hence, the residuals of the FF5-Normal model don't follow Normal distribution. And the FF5-Normal model is not adequate for the data.

\subsubsection{Model Comparison}

We compare models with AIC. Results in Table 6 show FF5-SSAEPD-EGARCH model has smaller AIC value than FF5-Normal model. That is, this new model is better than the one in Fama and French(2015). However, FF5-GARCH model or FF5-SSAEPD-GARCH model seem to be the best because it has the smallest AIC values. That means, models with GARCH is better than the ones with EGARCH. Also, since AIC values are the same for both FF5-GARCH and FF5-SSAEPD-GARCH, we conclude that, to capture fat-tailedness, GARCH equation is better than SSAEPD, which is consistent with what we found out in our previous researches.

\section{Conclusions and Future Extensions}

In this paper, US sector of services is studied. A new Fama-French 5-factor model (denoted as FF5-SSAEPD-EGARCH) is empirically tested. This new model uses the non-normal error term of SSAEPD of Zhu and Zinde-Walsh

Table 5. P-values of KS test.

\begin{tabular}{ccc}
\hline Model & FF5-SSAEPD-EGARCH & FF5-Normal \\
\hline US 5factors & 0.04 & 0.00 \\
North American 5 factors & 0.05 & 0.00 \\
Global 5 factors & 0.07 & 0.00 \\
\hline
\end{tabular}

Note: The null hypothesis of KS test is $H_{0}$ : Data follow a specified distribution. We set the significance level of all tests at $5 \%$. If the P-value of KS test is bigger than $5 \%$, then we do not reject the null hypothesis. Otherwise, we reject the null hypothesis. For example, We apply KS test for the FF5-SSAEPD-EGARCH model residuals with the null hypothesis of $H_{0}$ : FF5-SSEAPD-EGARCH model residuals are distributed as $\operatorname{SSAEPD}\left(\hat{\alpha}, \hat{p}_{1}, \hat{p}_{2}\right)$. For Global five factors, its $\mathrm{P}$-value is 0.07 , which is bigger than 0.05 . That means, under $5 \%$ significance level, we cannot reject the null hypothesis and conclude that the residuals from FF5-SSEAPD-EGARCH model follow SSAEPD.

\footnotetext{
${ }^{11}$ The null hypothesis $H_{0}$ : FF5-Normal residuals are distributed as $\operatorname{Normal}\left(\hat{\mu}, \hat{\sigma}^{2}\right)$.
} 
Table 6. AIC values.

\begin{tabular}{ccccccc}
\hline Model & FF5-SSAEPD-EGARCH & FF5-Normal & FF5-SSAEPD & FF5-GARCH & FF5-SSAEPD-GARCH & FF5-EGARCH \\
\hline US 5 factors & 4.16 & 4.19 & 4.90 & 4.14 & 4.14 & 4.18 \\
North Ame. 5 factors & 4.30 & 4.27 & 5.06 & 4.22 & 4.22 & 4.31 \\
Global 5 factors & 5.09 & 5.05 & 6.59 & 4.91 & 4.91 & 5.12 \\
\hline
\end{tabular}

Note: North Ame.=North American.

(2009) and EGARCH-type volatility of Nelson (1991) to extend the 5 factor model of Fama and French (2015). The return of services industry and 3 types of 5 factors (US five factors, North American five factors, Global five factors) from French's Data Library are analyzed and compared. Sample period is from Jul. 1990 to Feb. 2017. Likelihood Ratio test (LR) is used for parameter restriction test, Kolmogorov-Smirnov test (KS) for residual check and AIC for model comparison. Maximum Likelihood Estimation method (MLE) is used to estimate models via MatLab.

Empirical results show: 1) With EGARCH-typed volatilities and non-normal errors, the Fama-French 5 factors are still alive; 2) The new model fits the data better than Fama-French (2015)'s 5-factor model; 3) Models with GARCH-typed volatility are a little bit better than the ones with EGARCH-typed volatility; 4) To capture fat-tailedness, GARCH equation is better than SSAEPD; 5) Using SSAEPD, model can capture stronger left fat-tailedness.

Future extensions will include but not limited to the following: First, we can construct a new index for services industry; Second, other sectors can be analyzed; Last, different factors can be considered.

\section{References}

[1] Fama, E.F. and French, K.R. (2015a) A Five-Factor Asset Pricing Model. Journal of Financial Economics, 116, 1-22.

[2] Sharpe, W.F. (1964) Capital Asset Prices: A Theory of Market Equilibrium under Conditions of Risk. Journal of Finance, 19, 425-442.

[3] Lintner, J. (1965) The Valuation of Risk Assets and the Selection of Risky Investments in Stock Portfolios and Capital Budgets. Review of Economics and Statistics, 47, 13-37.

[4] Carhart, M.M. (1997) On Persistence in Mutual Fund Performance. Journal of Finance, 52, 57-82.

[5] Chan, H.W. and Faff, R.W. (2005) Asset Pricing and the Illiquidity Premium. Financial Review, 40, 429-458.

[6] Gregory, C., Hagmann, M. and Linton, O. (2012) Efficient Semiparametric Estimation of the Fama-French Model and Extensions. Journal of the Econometric, 80, 713-754.

[7] Hou, K., Xue, C. and Zhang, L. (2015) Digesting Anomalies: An Investment Approach. Review of Financial Studies, 28, 650-705. https://doi.org/10.1093/rfs/hhu068

[8] Hou, K, Xue, C. and Zhang, L. (2014) A Comparison of New Factor Models. Social 
Science Electronic Publishing, Rochester, NY.

[9] Singh, S. and Yadav, S.S. (2015) Indian Stock Market and the Asset Pricing Models. Procedia Economics \& Finance, 30, 294-304. https://doi.org/10.1016/S2212-5671(15)01297-6

[10] Chiah, M., Chai, D., Zhong, A. and Li, S. (2016) A Better Model? An Empirical Investigation of the Fama-French Five-Factor Model in Australia. International Review of Finance, 16, 595-638.

[11] Fama, E.F. and French, K.R. (2017) International Tests of a Five-Factor Asset Pricing Model. Journal of Financial Economics, 123, 441-463. https://doi.org/10.1016/j.jfineco.2016.11.004

[12] Guo, B., Zhang, W., Zhang, Y.J. and Zhang, H. (2017) The Five-Factor Asset Pricing Model Tests for the Chinese Stock Market. Pacific-Basin Finance Journal, 43, 84-106. https://doi.org/10.1016/j.pacfin.2017.02.001

[13] Li, L., Zhu, Q.Y. and Yang, Y.J. (2017) An Extension of FAMA and French 5-Factor Model Based on the SSAEPD Errors and the EGARCH-Type Volatilities. Asian Academic Research Association, Journal of Multidisciplinary (AARJMD), 4, 184-203.

[14] Zhu, D. and Zinde-Walsh, V. (2009) Properties and Estimation of Asymmetric Exponential Power Distribution. Journal of Econometrics, 148, 86-99. https://doi.org/10.1016/j.jeconom.2008.09.038

[15] Nelson, D.B. (1991) Conditional Heteroskedasticity in Asset Returns: A New Approach. Econometrica, 59, 347-370. https://doi.org/10.2307/2938260

[16] Fama, E.F. and French. K.R. (1992) The Cross-Section of Expected Stock Returns. Journal of Finance, 47, 427-465. https://doi.org/10.1111/j.1540-6261.1992.tb04398.x

[17] Griffin, J.M. (2002) Are the Fama and French Factors Global or Country Specific? Review of Financial Studies, 15, 783-803. https://doi.org/10.1093/rfs/15.3.783

[18] Chan, H.W. and Faff, R.W. (2003) An Investigation into the Role of Liquidity in Asset Pricing: Australian Evidence. Pacific-Basin Finance Journal, 11, 555-572. https://doi.org/10.1016/S0927-538X(03)00003-9

[19] Fama, E.F. and French, K.R. (2012) Size, Value, and Momentum in International Stock Returns. Journal of Financial Economics, 105, 457-472. https://doi.org/10.1016/j.jfineco.2012.05.011

[20] Chai, D., Faff, R. and Gharghori, P. (2013) Liquidity in Asset Pricing: New Australian Evidence Using Low-Frequency Data. Australian Journal of Management, 38, 375-400. https://doi.org/10.1177/0312896213489143

[21] Fama, E.F. and French, K.R. (2013) A Four-Factor Model for the Size, Value, and Profitability Patterns in Stock Returns. SSRN Electronic Journal.

[22] Neyman, J. and Pearson, E.S. (1993) On the Problem of the Most Efficient Tests of Statistical Hypotheses. Philosophical Transactions of the Royal Society A: Mathematical, Physical and Engineering Sciences, 231, 289-337. https://doi.org/10.1098/rsta.1933.0009 
Submit or recommend next manuscript to SCIRP and we will provide best service for you:

Accepting pre-submission inquiries through Email, Facebook, LinkedIn, Twitter, etc. A wide selection of journals (inclusive of 9 subjects, more than 200 journals)

Providing 24-hour high-quality service

User-friendly online submission system

Fair and swift peer-review system

Efficient typesetting and proofreading procedure

Display of the result of downloads and visits, as well as the number of cited articles Maximum dissemination of your research work

Submit your manuscript at: http://papersubmission.scirp.org/

Or contact am@scirp.org 